\title{
O Modelo Pedagógico idealizado por Maria Montessori: aplicabilidade do Método e contribuições para o desenvolvimento Infantil
}

\author{
Maria Marile Rodrigues ${ }^{1}$; Gislene Farias de Oliveira ${ }^{2}$
}

Resumo: O desenvolvimento infantil, ao longo dos anos se tornou de grande interesse para estudiosos e pesquisadores da área, entre eles podemos destacar a italiana Maria Montessori, primeira médica a se formar na Itália - pela universidade de Roma - e por isso, ficou carinhosamente conhecida como a 'doutora' Montessori, que dedicou parte de sua vida a elaborar estratégias e recursos para compreensão dos processos de aprendizagem infantil, respeitando ritmos, individualidades, valorizando a personalidade, capacidades sensoriais, intelectuais e emocionais de cada ser em processo de formação. Dessa forma a presente pesquisa de cunho meramente bibliográfica, se destina a pesquisar sobre o modelo pedagógico defendido pela autora, a aplicabilidade, ambientação e possibilidades de aprendizagem, considerada uma das mais importantes propostas para o desenvolvimento infantil.

Palavras- Chave: Modelo pedagógico. Maria Montessori, Aprendizagem.

\section{The pedagogical model designed by Maria Montessori: applicability of the method and contributions to Child Development}

\begin{abstract}
Child development over the years has become of great interest to scholars and researchers of the area, among them we can highlight the Italian Maria Montessori, the first doctor to graduate in Italy - by the University of Rome - and therefore, Known as Dr. Montessori, who dedicated part of her life to developing strategies and resources for understanding children's learning processes, respecting rhythms, individualities, valuing the personality, sensory, intellectual and emotional capacities of each being in the process of formation. Thus, the present research of a purely bibliographical nature is intended to research on the pedagogical model advocated by the author, the applicability, setting and learning possibilities, considered one of the most important proposals for child development.
\end{abstract}

Keywords: Pedagogical model. Maria Montessori, Apprenticeship.

\section{Introdução}

As concepções teóricas a cerca dos processos de desenvolvimento infantil, foram apresentadas por vários educadores e pensadores, entre elas podemos destacar o modelo pedagógico montessoriano. Cuja finalidade consiste em estabelecer harmonia entre o corpo, intelecto e desejo, provocando o indivíduo a aprender com autonomia.

\footnotetext{
${ }^{1}$ Licenciada em Pedagogia pela Universidade Vale do Acaraú - UVA/CE. Mestranda em Educação pela Anne Sullivan University. Professora Efetiva Municipal em Juazeiro do Norte - CE. E-mail: marile.relva@ hotmail.com.

${ }^{2}$ Doutorado em Psicologia Social pela Universidade Federal da Paraíba - UFPB e Pós Doutorado em Ciências da Saúde pela Faculdade de Medicina do ABC - São Paulo. E-mail: gislenefarias@gmail.com.
} 
Id on Line Revista Multidisciplinar e de Psicologia

Id on Line Multidisciplinary and Psycology Journal

Por ter dedicado toda á sua vida ao desenvolvimento infantil, Maria Montessori se tornou admirada, e seus métodos são copiados no mundo inteiro até os dias atuais. Idealizou e produziu um vasto material pedagógico para auxilio dos professores, elaborou estratégias para ambientar e adaptar os mobiliários tornando-os acessível ás crianças, acreditando que dessa forma tornaria - os autônomos. Suas ideias revolucionárias despertaram interesses de algumas lideranças políticas e religiosas. Assim a educadora percorreu o mundo divulgando e aplicando seu modelo educativo. Foi ainda alvo de muitas criticas, por aqueles que acreditavam que a educadora restringia a proposta e que somente os discípulos treinados por ela estavam aptos a desenvolver tal método.

Dentro dessa perspectiva, existem escolas e professores espalhados no mundo inteiro que tem como referencia a metodologia montessoriana,porém ainda existe ausência de informação e conhecimento. Esse despreparo do professor tem deixado a proposta fragmentada, causando rejeição dos profissionais, que por desconhecer tem dificuldades de utilizá - la ,criando estigmas generalizados.A pesquisa segue em análises bibliográficas de autores que versam sobre as obras e o legado da educadora.

\section{Maria Montessori: anos de dedicação ao desenvolvimento infantil e respeito à criança}

Maria Tecla Artemesia Montessori nasceu em 31 de agosto de 1879 na cidade de Chiaravalle, Itália. Seu pai era oficial do Ministério das Finanças Alessandro Montessori, que cultuava hábitos conservadores Sua mãe, Renilde Stoppani, era bem educada e aparentava praticar hábitos de leituras. Ainda na infância Montessori demonstrava suas habilidades, e apresentava interesse superior às demais crianças para o aprendizado, tendo total apoio de sua mãe. (NICOLAU, 2005).

Entre suas habilidades destacava-se o interesse pela matemática, deixando-a convencida de que seria uma futura engenheira, contrariando a vontade de seu pai, que desejava que ela exercesse a carreira docente, profissão adequada para moças da época. $\mathrm{O}$ seu interesse pelos números não foi suficiente para que a idéia fosse adiante, mais tarde decidiu estudar medicina, um curso que na época era destinado aos rapazes, para levar adiante tal decisão teve que enfrentar o preconceito e a exclusão, tendo que estudar em um ambiente totalmente 
Id on Line Revista Multidisciplinar e de Psicologia

Id on Line Multidisciplinary and Psycology Journal

masculino POLARD (1990). Porém, as adversidades não se configuram como obstáculo para Montessori, se tornando a primeira mulher na Itália a se graduar como Doutora em medicina, um grande marco para época (OLIVEIRA, 2010).

\begin{abstract}
Montessori recebeu o título de doutora em medicina e cirurgia, tornando-se a primeira médica Italiana, após impressionar na apresentação de sua tese para dez homens. E nesse mesmo ano ela participou do congresso Internacional pelos Direitos da Mulher, que aconteceu em Berlim. Logo após de formada essa doutora recebe um convite para trabalhar no Hospital San Giovanni como assistente. (SILVESTRIN, 2012 apud NICOLAU, 2005).
\end{abstract}

Inicia-se então uma carreira promissora, passando a dedicar-se a atendimentos particulares em clínicas psiquiatras, foi a partir dessa experiência que despertou em Montessori o interesse pelas crianças com deficiência, em uma época que o entendimento sobre os procedimentos adotados para tais sujeitos, ainda não era acessível. (TEZZARI, 2009). Desde então, iniciou suas pesquisas científicas buscando referencia nas abras de autores como: Edouard Séguin e Jean Itard,esses mesmos autores serviram de modelos para a construção de seu modelo pedagógico.

A fim de ampliar suas pesquisas, e seus conhecimentos pedagógicos a doutora Montessori cursou psicologia experimental e filosofia, buscando entender e elaborar métodos que pudesse ser utilizado pelas escolas primárias. (SILVESTRIN, 2012). Anos de dedicação estudo e pesquisa lhe renderam um convite para ocupar-se da educação de crianças carentes em um cortiço, que mais tarde daria origem a casa dei Bambini,e foi então através dessa iniciativa que surgiram suas contribuições para a educação mundial.(POLLARD,1990).

\title{
A Pedagogia Montessoriana e as contribuições para o Desenvolvimento Infantil
}

Ao expor suas idéias e colocá-las em prática, através dos resultados apresentados na casa dei Bambini,Montessori passou a ser conhecida no mundo realizando conferências,seminários,congressos e divulgando sua proposta, instalando outras escolas em outras regiões do mundo,(POLLARD,1990).Seu acervo bibliográfico e suas pesquisas,possuem características contemporânea,todo esse aparato metodológico, foi amplamente divulgado pela 
Id on Line Revista Multidisciplinar e de Psicologia

Id on Line Multidisciplinary and Psycology Journal

própria educadora em vários países,abordando os principais fatores e recursos favoráveis ao desenvolvimento infantil.

\begin{abstract}
A pedagogia Montessoriana está inserida no movimento escolanovista e teve grande importância e destaque para os jardins de infância e para as primeiras séries do ensino, pois se opôs aos métodos tradicionais que não respeitavam as necessidades e os mecanismos evolutivos do desenvolvimento da criança, que são extremamente importantes nessa faixa etária. (CESÁRIO, 2007).
\end{abstract}

. Dentre os princípios da pedagogia montessoriana, estão o respeito pelo potencial de cada indivíduo, o tempo de aprendizagem e as limitações de cada um. A educadora defendia a liberdade e autonomia da criança e que esta pudesse escolher quais atividades desejaria participar. O diferencial centrava-se no estímulo por meio da das atividades lúdicas e práticas. Os recursos didáticos montessorianos foram produzidos com intuito de possibilitar o acesso da criança ao conhecimento consciente a partir de ações experimentais, compreendendo que dessa forma os indivíduos se tornam autônomos através das atividades praticadas. Para Montessori, o principal fundamento do desenvolvimento da criança é a concentração. Ela precisa ser estimulada a descobrir como se concentrar e para isso tem necessidade de experimentar situações que exercite - a. (SILVEIRA, 2014).

A variedade de recursos desenvolvidos por Maria Montessori, todos com características e adequados a faixa etária de cada nível de desenvolvimento referenda a seriedade e o compromisso com que a educadora exercia a profissão.

Mandei construir mesinhas de formas variadas que não balançassem, e tão leves que duas crianças de quatro anos pudessem facilmente transportá-las; cadeirinhas, de palha ou de madeira, igualmente bem leves e bonitas e que fossem uma reprodução, em miniatura, das cadeiras de adultos, mas proporcionadas às crianças. (...) Também faz parte desta mobília uma pia bem baixa, acessível às crianças, de três ou quatro anos, guarnecida de tabuinhas laterais, laváveis, para o sabonete, as escovas e a toalha. Todos estes móveis devem ser baixos, leves e muito simples. Pequenos armários fechados por cortinas ou por pequenas portas, cada um com sua chave própria; a fechadura ao alcance das mãos das crianças, que poderão abrir ou fechar este moveis e acomodar dentro deles seus pertences. (MONTESSORI, 1965, p. 42)

Desta forma, Montessori classificou os materiais produzidos em cinco grupos nomeados pela autora de: Exercícios Para a Vida Cotidiana, Material Sensorial, de Linguagem, Matemática e Ciências. Materiais estes constituídos por peças concretas das mais variadas 
formas e tamanhos, objetos que abrem e fecha e de encaixe; botões para abotoar; coloridos. Coleções de superfícies de diferentes texturas, além de objetos sonoros. Há ainda o material dourado que desperta no aluno o poder de concentração. Além de, estabelecer relações de quantidades, proporções, e contribui para a contagem e a realização de cálculos. (MORAES, 2009).

A seleção do uso do material é realizada pela própria criança de acordo com sua necessidade, sendo que a utilização dos recursos é feita de maneira individual. Os professores auxiliam no processo de aprendizagem

\footnotetext{
...Nas escolas tradicionais a professora conhece o comportamento imediato de seus alunos e sabe que deve cuidar deles e o que fazer para instruí-los; enquanto a professora montessoriana encontra diante de si uma criança que, por assim dizer, não existe ainda. (MONTESSORI, 1987, p.297)
}

Montessori defendia ambientes favoráveis e propícios á aprendizagem, já que cada criança nasce com a capacidade de aprender se forem dadas oportunidades. $\mathrm{O}$ foco central parte do princípio de que a aprendizagem é conquistada pela própria criança. Estimular a concentração conduzindo e permitindo que os alunos mostrem seu potencial através da pratica, os professores tem papel de conduzir e motivar o aluno no processo de aprendizagem, pois a educação não é algo estático, se conduz para a formação integral do indivíduo associado à vontade do aprender.

A mediação do professor em algumas ações é substituída por outro aluno, que já domina o assunto e o auxilia gerando aprendizagem coletiva. O que já sabe realiza uma breve revisão do conteúdo e o que está aprendendo sente-se estimulado em aprender através dos próprios colegas e fazendo uso da mesma linguagem. A presença do professor é constante, porém, só realiza intervenções quando necessário, acompanhando e mediando às ações desenvolvidas pelas crianças. 
Id on Line Revista Multidisciplinar e de Psicologia

Id on Line Multidisciplinary and Psycology Journal

\section{O Material Montessoriano e a carência de informação para a aplicabilidade}

O material montessoriano foi desenvolvido como parte do complemento do método, cuja função é contribuir no desenvolvimento da aprendizagem, através de ações concretas, até a abstração total do conhecimento aprendido. (CLEMES, 2016). Os espaços das aulas Montessorianas são abastecidos os com um vasto material sempre organizado e disponível para o acesso e manipulação das crianças. Os estímulos provocados pela manipulação dos materiais funcionam como impulso para despertar nos indivíduos o desejo de aprender.

As escolas que se assemelham e/ou adotam esse modelo pedagógico precisam de muito referencial teórico/prático para que não cometa erros e ofereça a seu público o processo pela metade, ainda existe falta de compreensão da teoria montessoriana.Dessa forma,muitos educadores encontram dificuldades de aplicá -lo, tecendo duras críticas as idéias de Maria Montessori,por falta de informações e conhecimentos.

É de fundamental importância que o professor conheça a estrutura e funcionamento do método, para que está venha a surtir efeitos positivos nos espaços escolares. Criar condições que favoreçam a aprendizagem, oportunizando a criança a manifestar suas vontades e capacidades fazendo uso do seu desempenho psíquico e intelectual. Para Montessori é missão do professor.

\footnotetext{
Sua missão é preparar o ambiente, procurar o material de concentração, iniciar exatamente a criança. Deve ser sempre serena, deve estar sempre pronta para acudir quando for chamada, entregar-se às necessidades do amor e de confidências da criança, que são para ela toda uma preparação de vida. Diretora do ânimo deve ela ter uma formação, sobretudo moral. (MONTESSORI, apud. Angotti, 2003, p. 44).
}

Dentro dessa perspectiva, os professores não conseguem compreender a filosofia do método abordado, na maioria das vezes por total desconhecimento e/ou resultados da má formação. A educadora acreditava que somente os professores instruídos por ela estavam aptos a usar seu método (POLLARD, 1990). O autor também ressalta que valorizar o potencial infantil, e possibilitar um ambiente favorável é garantia de aprendizagem e autonomia da criança. Para tanto é necessário que o docente faça uso de um vocabulário acessível e tenha dedicação total ao método proposto. 
Id on Line Revista Multidisciplinar e de Psicologia

Id on Line Multidisciplinary and Psycology Journal

\section{Metodologia}

O estudo foi realizado através de pesquisa bibliográfica, de cunho qualitativo, durante os meses de Julho/Agosto de 2016. Foram realizadas consultas em artigos acadêmicos como: documentos, oficiais (RCNEI, 1998) fontes bibliográficas (NICOLAU, 2005), (DUARTE, 2014), (SILVESTRIN, 2012), (TEZZARI, 2009), (MORAES, 2009) e consulta em sites. Buscou-se coletar as informações necessárias para ampliar as discussões a cerca do modelo pedagógico montessoriano e quais contribuições oferecem ao desenvolvimento infantil na educação contemporânea.

\section{Resultados e Discussões}

A presente pesquisa é resultado de um estudo de cunho bibliográfico, e tem como foco central investigar e analisar as contribuições da educadora Maria Montessori para o desenvolvimento infantil. Para tanto foram consultados um vasto referenciais bibliográficos publicados por (ALMEIDA, 2005), (BÓZIO, 2004), (ANGOTTI, 2003), (LAGOA, 1981), (VOGOTSKY, 1997), (NUNES, 2009). Confirmam-se então as inúmeras contribuições da autora, através das diferentes referências consultadas, pelos diferentes autores sobre a temática proposta por esta pesquisa. Os artigos abordam desde a formação e dedicação da educadora até as ações e materiais produzidos por ela para facilitar os processos de aprendizagem das crianças.

Os acervos bibliográficos apontam experiências que surtiram efeitos em todos os países por onde ela visitou. A formação dos professores interessados em trabalhar com a proposta era realizada por ela mesma. Se tornando uma exigência da autora, que somente dessa forma os educadores se tornariam autênticos, realizar adaptações e ajustes a proposta jamais seria permitido. Essa iniciativa fez com que seu método fosse alvo de duras críticas, as pessoas contrárias as suas idéias alegavam que irrestrita lealdade limitava a proposta somente aos seus escolhidos e/ou interessados.

Conhecido e aplicados em todo mundo esse modelo pedagógico ainda causa estranheza e espanto aos professores, a falta de conhecimento faz com que muitos educadores 
Id on Line Revista Multidisciplinar e de Psicologia

Id on Line Multidisciplinary and Psycology Journal

não acreditem que essa ferramenta pedagógica possa gerar aprendizagem nas crianças, e que esse modelo só funcionaria com números de alunos bem reduzidos. Como nossas salas de aulas estão sempre com a capacidade de alunos superior ao que determina a legislação, seria perda de tempo apostar na ideia. Assim, hoje algumas escolas que adotaram a pedagogia montessoriana divulgam a idéia, realizam a formação pedagógica do professor, e toda ambientação do espaço escolar.

\section{Considerações Finais}

Os resultados iniciais dessa pesquisa considera as mais variadas possibilidades de aprendizagens proporcionadas pelo método montessoriano, através da manipulação dos materiais,da organização do ambiente,e das metodologias idealizadas pela educadora, cujo principal objetivo remetem a formação cidadã, valores cristãos e culturais. Pode - se identificar ainda, análises das sugestões propostos em suas obras que esse modelo pedagógico faz parte da contemporaneidade e são utilizados nos dias de hoje, se tornando ferramenta de auxilio pedagógico principalmente nas séries iniciais.

A falta de entendimento da proposta e o despreparo dos professores, que vão desde a sua formação acadêmica inicial até sua prática negligente no chão da sala de aula, fazem com que a proposta sofra adequações e mudanças e perca sua funcionalidade. Há ainda uma corrente daqueles professores que acreditam que esse modelo pedagógico é fantasioso demais, e só funciona com um número de criança reduzido, devendo ser ajustado, para possa ser utilizados, já que salas superlotadas é uma realidade nos dias atuais. Desta forma, para colocar em prática a proposta montessoriana, se faz necessários, investimentos financeiros, ambientes e materiais pedagógicos adequados, formação para os professores e compreensão da filosofia do método é fundamental para que se tenha êxito na proposta.

Assim a presente pesquisa propõe uma reflexão sobe o legado da educadora, sua dedicação, e como esta contribuiu para que todas as crianças se desenvolvessem independente de sua condição social e física. As teorias dos pensadores desenvolvidas há séculos nos remetem a compreensão e como se constituiu a História da Educação, quem foram os pioneiros e quais os desafios enfrentados por estes. 
Id on Line Revista Multidisciplinar e de Psicologia

Id on Line Multidisciplinary and Psycology Journal

\section{Refrências}

ALMEIDA, T. Maria Montessori: uma história no tempo e no espaço. Rio de Janeiro: Obrape, 2005.

ANGOTTI, Maristela. O trabalho docente na pré-escola. SP: Pioneira Thomson Learning, 2003. http://www.montessori-al.com.br/cmm/mariamontessori.pdfacesso em 02 ago 2016.

BÓZIO, Eliana Rabelo. Software de Treinamento e de Divulgação do Método Montessori, 2004.

BRASIL. Ministério da Educação e do Desporto. Secretaria de Educação Fundamental. Referencial curricular nacional para a educação infantil / Ministério da Educação e do Desporto, Secretaria de Educação Fundamental. — Brasília: MEC/SEF, 1998. 3v.: il

CAMBI, F. História da Pedagogia. São Paulo: Ed. UNESP, 1999.

COMÉNIO, J. A. Didáctica Magna. 4. ed. Lisboa: Fundação Calouste Gulbenkian, 1996

CLEMES, Simone Clemens. Método Montessori e Superdotação na infância, Material didático Montessorianohttps://simoneclemens.wordpress.com/2016/07/25/como-saber-se-seualunofilho-nao-esta-sendo-desafiado-intelectualmente-osuficiente/acesso em:01 de ago/2016.

CESÁRIO, Priscila Menarin Cesário. Quem é a professora de crianças menores de 6 anos para Maria Montessori? Uma análise a partir de suas obras educacionais. Universidade Federal de São Carlos Centro de Educação e Ciências Humanas, São Carlos junho de 2007.

DUARTE, A, P, M. Contribuições de Maria Montessori para as práticas pedagógicas na educação Infantil.Adenita Pereira Mota Duarte.Sociedade Cultural e Educacional de Itapeva.Faculdade de Ciências Sociais e Agrárias de Itapeva,2014.

LAGOA, V. Estudo do sistema Montessori: fundamentado na análise experimental do comportamento. São Paulo: Loyola, 1981

MORAES. M, S, L. Escola Montessori: um espaço de conquista e redescoberta. 2009. 130 f. Dissertação (Mestrado em Educação) Centro Universitário La Selle,Canoas,2009

MONTESSORI, M. Pedagogia Científica: a descoberta da criança. São Paulo. Flanboyant.1965.309p..

Mente absorvente. Rio de Janeiro: Editorial Nórdica, 1987. 
NICOLAU, Marieta Lúcia Machado. A formação de Maria Montessori. In. Viver mente e cérebro. Coleção memória da Pedagogia - Montessori, São Paulo. Duetto Editorial, 2005.

NUNES, Denise Nunes, Emília Tamara, Milene Cacciamani, Neide Lopes, Vânia Izabel, Viviane de Castro. Pedagogia, 2009. Disponível em: http://coracoespelapaz.blogspot.com.br/2012/09/quem-e-maria-montessori-e-sua.html. Acesso em 12.12.2016.

OLIVEIRA, Delcy Lacerda de. Construção de instrumento de avaliação da aprendizagem em escola montessoriana / Tese de Mestrado Apresentada à Fundação Cesgranrio. 2010.

POLLARD, M. Maria Montessoi: São Paulo: Editora Globo 1990.64 p. Coleção Personagens que mudaram o mundo.Os Grandes Humanistas.

SILVESTRIN, P. Método Montessori e inclusão Escolar: articulações possíveis. UFRGS. Faculdade de Educação/PPGEDU - Curso de Especialização em Educação Especial e processos inclusivos - Porto Alegre 2012.

SILVEIRA, Reviane Francy Silva da; OLIVEIRA, Tiago Mendes de; SOUZA, Gilson Luiz Rodrigues. Maria Montessori: "Uma Vida Dedicada às Crianças" e sua Colaboração à Educação. Revista Brasileira de Educação e Cultura - ISSN 2237-3098 Centro de Ensino Superior de São Gotardo Número X Jul-dez 2014 Trabalho 05 Páginas 47-51

TEZZARI, Mauren Lúcia. Educação Especial e ação docente: da medicina a educação/Porto Alegre 2009 235f.

VIGOTSKY, Lev, A Formação Social da Mente: O Desenvolvimento dos Processos Psicológicos Superiores, são Paulo, Ed. Martis 1997.

Como citar este artigo (Formato ABNT):

RODRIGUES, M.M.; OLIVEIRA, G.F. O Modelo Pedagógico idelizado por Maria Montessori: aplicabilidade do método e contribuições para o Desenvolvimento Infantil. Id on Line Revista Multidisciplinar e de Psicologia, Janeiro de 2017, vol.10, n.33, Supl 2. p. 139-148. ISSN: 1981-1179. 